\title{
Trends in Hospital Admission Due to Diseases of the Eye and Adnexa in the Past Two Decades in England and Wales: An Ecological Study
}

\author{
Hamzeh Mohammad Alrawashdeh $\mathbb{D}^{1, *}$, Abdallah Y Naser $\mathbb{D}^{2, *}$, Hassan Alwafi ${ }^{3,4}$, \\ Amal Khaleel AbuAlhommos $\left(\mathbb{D}^{5}\right.$, Zahra Jalal ${ }^{6}$, Vibhu Paudyal $\mathbb{D}^{6}$, Dina M Abdulmannan $\mathbb{D}^{3}$, \\ Fadi Fouad Hassanin ${ }^{7}$, Sara Ibrahim Hemmo ${ }^{2}$, Fawaz Al Sarireh ${ }^{8}$ \\ 'Department of Ophthalmology, Sharif Eye Centers, Irbid, Jordan; ${ }^{2}$ Department of Applied Pharmaceutical Sciences and Clinical Pharmacy, Faculty of \\ Pharmacy, Isra University, Amman, Jordan; ${ }^{3}$ Faculty of Medicine, Umm Alqura University, Mecca, Saudi Arabia; ${ }^{4}$ Alnoor Specialist Hospital, Ministry of \\ Health, Mecca, Saudi Arabia; ${ }^{5}$ Pharmacy Practice Department, Clinical Pharmacy College, King Faisal University, Alhasa, Saudi Arabia; ${ }^{6}$ School of \\ Pharmacy, University of Birmingham, Birmingham, UK; ${ }^{7}$ Department of Medicine, University of Jeddah, Jeddah, Saudi Arabia; ${ }^{8}$ Department of \\ Ophthalmology, College of Medicine, University of Mutah, Karak, Jordan
}

*These authors contributed equally to this work

Correspondence: Abdallah Y Naser; Hamzeh Mohammad Alrawashdeh, Email abdallah.naser@iu.edu.jo; dr_hmsr@yahoo.com

Purpose: To investigate the trends of hospital admissions concerning diseases of the eye and adnexa in the United Kingdom in the past 20 years.

Materials and Methods: An ecological study was conducted using hospital admission data taken from the Hospital Episode Statistics database in England and the Patient Episode Database for Wales. Hospital admissions data for diseases of the eye and adnexa were extracted for the period between April 1999 and March 2019. The trend in hospital admissions was assessed using a Poisson model.

Results: Hospital admission rate for diseases of the eye and adnexa increased by $73.8 \%$ [from 7.48 (95\% CI 7.45-7.50) in 1999 to 13.00 (95\% CI 12.97-13.02) in 2019 per 1000 persons, trend test, $\mathrm{p}<0.001$ ]. The most common cause of hospitalisation for diseases of the eye and adnexa was disorders of the lens (62.3\%), followed by disorders of the choroid and retina (14.2\%), followed by disorders of the eyelid, lacrimal system and orbit (11.5\%). Hospital admission rate among males increased by $91.2 \%$ [from 6.19 ( $95 \%$ CI 6.16-6.22) in 1999 to 11.83 (95\% CI 11.80-11.87) in 2019 per 1000 persons]. Hospital admission rate among females increased less sharply by $63.2 \%$ [from 8.71 (95\% CI 8.68-8.75) in 1999 to 14.22 (95\% CI 14.18-14.26) in 2019 per 1000 persons].

Conclusion: There are clear gender and age trends in the epidemiology of hospital admissions related to eye and adnexa disorders. Further observational studies are warranted to identify other risk factors for these important causes of hospitalisation and understanding of differential trends.

Keywords: admission rate, adnexa, ecological study, England, eye, hospitalisation, United Kingdom, Wales

\section{Introduction}

Untreated eye diseases, particularly cataracts, ${ }^{1}$ are considered the principal cause of blindness worldwide. The majority of people with visual impairment are elderly and fall in the age group 50 years and above. More than $80 \%$ of people in this age group suffer from eye diseases. ${ }^{2}$ The United Kingdom (UK) ranked number four after Russia, Turkey, and Germany in Europe and number 21 worldwide in the list of countries by population, with an estimated population of $67,886,011$ people (about $0.87 \%$ of the total world population) in 2020 , according to the United Nations (UN) data. The UK population in mid-2019 was 66,796,807, of which 59,439,840 (89.0\%) were living in England and Wales. Between 1999 and 2020, the UK population increased by 9,170,157 (the estimated number was 58,715,854 in 1999). ${ }^{3,4}$ In the UK, in 2000 , the median age was 37.6 years, reaching 40.5 in 2020 with a dramatic increase by 0.73 years every five years. 
Similarly, the life expectancy increased from 80.6 and 76.1 years in 2000 to 83.3 and 80.2 years in 2020 for females and males, respectively (the average increase was 0.68 and 1.03 years every five years for females and males, respectively). ${ }^{4}$ Both the large population and high life expectancy increase the demands on health services as older people are more prone to develop chronic illnesses with multiple morbidities, including age-related eye diseases and associated visual impairment. ${ }^{5,6}$

Ocular adnexa is a term given to the accessory structures attached to, close to, or surrounding the eye. They include eyelids, eyelashes, conjunctiva, extraocular muscles, lacrimal apparatus, and orbit. ${ }^{7,8}$ The eyes and adnexa are subject to several conditions due to congenital, developmental, structural, metabolic, autoimmune, infectious, inflammatory, traumatic, degenerative, and neoplastic disorders. Diseases that affect the globe and its surrounding tissues may present diagnostic and therapeutic challenges to health-care providers, especially ophthalmologists and dermatologists. ${ }^{9}$ Careful observation and extensive knowledge of the most frequent diseases of the eye and adnexa, which lead to early detection, diagnosis, and management of ocular diseases, are crucial for establishing the desired outcomes.

Nowadays, the advancement in treating eye conditions has decreased the incidence of ocular complications, such as complications related to diabetic retinopathy. ${ }^{6,10,11}$ Early diagnosis and treatment of eye diseases is essential to prevent visual impairment and improve quality of life. ${ }^{6}$ One way to monitor the quality of healthcare management for patients suffering from eye diseases is to explore the associated rate of hospital admissions. Hospital admission rates are important measures for health-care monitoring and assessment of interventions. ${ }^{12}$ Admission rates are mainly influenced by the number of new cases of disease, and it is an important measure of healthcare quality. ${ }^{12,13}$ Thus, this study aims to investigate the trends of hospital admissions concerning diseases of the eye and adnexa in the UK in the last two decades.

\section{Materials and Methods}

\section{Study Sources and the Population}

This is an ecological study using publicly available data taken from the two main medical databases in England and Wales: the Hospital Episode Statistics (HES) database in England ${ }^{14}$ and the Patient Episode Database for Wales (PEDW). ${ }^{15}$ These two medical databases have been used previously to explore the trends of different health outcomes and the associated hospital admissions. ${ }^{16-21}$

Hospital admission data were collected for the period between April 1999 and March 2019. ${ }^{14,15}$ The HES and PEDW databases contain hospital admission data for all diseases of the eye and adnexa for patients from all age categories, reported as follows: below 15 years, 15-59 years, 60-74 years, and 75 years and above. We identified hospital admissions related to diseases of the eye and adnexa using the tenth version of the International Statistical Classification of Diseases (ICD-10) system. All diagnostic codes for diseases of the eye and adnexa (H00 - H59) were used to identify all hospital admissions related to various types of diseases of the eye and adnexa in England and Wales. The World Health Organization (WHO) developed a medical classification for diseases of the eye and adnexa known as the International Statistical Classification of Diseases and Related Health Problems 10th Revision (ICD-10) Code range (H00-H59). It includes ICD-10 codes for eyelid, orbit, and lacrimal systems disorders (H00-H05), conjunctival disorders (H10-H11), corneal, scleral, ciliary body, and iris disorders (H15-H22), lenticular disorders (H25$\mathrm{H} 28$ ), retinal and choroid disorders (H30-H36), glaucoma (H40-H42), vitreous body and globe disorders (H43-H44), optic nerve and visual pathway disorders (H46-H47), ocular muscles, binocular movement, refraction, and accommodation disorders (H49-H52), blindness and visual disturbances (H53-H54), other eye and adnexal disorders (H55-H57), and intra- and postoperative complications (H59-H59). ${ }^{22}$

HES and PEDW databases record all hospital admissions, outpatients and accident and emergency (A\&E) activities performed at all National Health Service (NHS) trusts and any independent sector funded by NHS trusts. Data for hospital admissions in England and Wales are available from the years 1999/2000 onwards. Available data include patient demographics, clinical diagnoses, procedures, and duration of stay. HES and PEDW data are checked regularly to ensure their validity and accuracy. ${ }^{14,23}$ To calculate the annual hospital admission rate for diseases of the eye and adnexa, we collected mid-year population data for the period between 1999 and 2019 from the Office for National Statistics (ONS). ${ }^{3}$ 


\section{Ethical Approval}

Hospital admissions, mortality, and population data are publicly available as anonymised data. Therefore, there was no need to obtain ethical approval for the study.

\section{Statistical Analysis}

Annual hospital admission rates related to diseases of the eye and adnexa with $95 \%$ confidence intervals (CIs) were calculated using the number of hospital admissions related to each type of disease of the eye and adnexa for each age group divided by the mid-year population of the same age group of the same year. The trend in hospital admissions was assessed using a Poisson model. All analyses were performed using SPSS version 27 (IBM Corp, Armonk, NY, USA).

\section{Results}

A total of 11,691,873 hospital admission episodes related to diseases of the eye and adnexa were reported in England and Wales during the study period between 1999 and 2019. Females contributed to 56.9\% of the total number of hospital admissions, accounting for 6,663,566 hospital admission episodes with an average of 333,178 admissions per year. Hospital admission rate among males increased by $91.2 \%$ [from 6.19 (95\% CI 6.16-6.22) in 1999 to 11.83 (95\% CI $11.80-11.87$ ) in 2019 per 1000 persons]. Hospital admission rate among females increased less sharply by $63.2 \%$ [from 8.71 (95\% CI 8.68-8.75) in 1999 to 14.22 (95\% CI 14.18-14.26) in 2019 per 1000 persons].

The total annual number of hospital admissions for diseases of the eye and adnexa for various reasons rose from 389,889 in 1999 to 772,452 in 2019 , representing an increase in hospital admission rate of $73.8 \%$ [from 7.48 (95\% CI 7.45-7.50) in 1999 to 13.00 (95\% CI 12.97-13.02 in 2019 per 1000 persons, trend test, $\mathrm{p}<0.01$ ).

The most common cause of hospitalisations for diseases of the eye and adnexa were disorders of the lens (62.3\%), followed by disorders of the choroid and retina (14.2\%), followed by disorders of the eyelid, lacrimal system and orbit (11.5\%) (Table 1).

During the past two decades, the highest increase in rate of hospital admissions was observed in disorders of the choroid and retina, followed by disorders of the optic nerve and visual pathways, followed by visual disturbances and blindness at 3.6-fold, 1.9-fold, and 1.2-fold, respectively. On the other hand, the rate of hospital admissions due to disorders of the eyelid, lacrimal system and orbit, and disorders of ocular muscles, binocular movement, accommodation and refraction decreased by $7.7 \%$ and $4.1 \%$, respectively (Figure 1), Table 2 .

Considering age group variations in diseases of the eye and adnexa-related hospital admissions, the age group 75 years and above accounted for $49.0 \%$ of the total number of hospital admissions related to diseases of the eye and adnexa, followed by the age group 60-74 years with $31.4 \%$, then the age group $15-59$ years with $16.2 \%$. The highest increase in rate of hospital admissions related to diseases of the eye and adnexa was for the age group 60-74 years, which increased by $69.7 \%$ [from 16.52 (95\% CI 16.43-16.62) in 1999 to 28.03 (95\% CI 27.92-28.13) in 2019 per 1000 persons]. Hospital admission rate among patients aged 75 years and above increased by $57.0 \%$ [from 47.10 (95\% CI 46.89 47.31) in 1999 to 73.96 (95\% CI 73.73-74.19) in 2019 per 1000 persons]. Hospital admission rate among patients aged 15-59 years increased by $48.4 \%$ [from 2.29 (95\% CI 2.27-2.31) in 1999 to 3.40 (95\% CI 3.38-3.42) in 2019 per 1000 persons]. Hospital admission rate among patients below 15 years increased by $1.4 \%$ [from 1.92 (95\% CI 1.90-1.95) in 1999 to 1.95 (95\% CI 1.92-1.98) in 2019 per 1000 persons] (Figure 2).

\section{Hospital Admission Rate by Gender}

Overall, diseases of the eye and adnexa-related hospital admission rates were higher among females compared to males (Figure 3). The majority of hospital admissions were more common among females, except for disorders of the conjunctiva, disorders of the sclera, cornea, iris and ciliary body, and disorders of the vitreous body and globe, which were more common among males (Figure 4). 
Table I Percentage of Hospital Admissions from Total Number of Admissions per ICD Code During the Study Period

\begin{tabular}{|l|c|c|}
\hline ICD Code & Description & $\begin{array}{c}\text { Percentage from Total Number of } \\
\text { Admissions }\end{array}$ \\
\hline $\mathrm{H} 00-\mathrm{H} 05$ & Disorders of eyelid, lacrimal system and orbit & $11.5 \%$ \\
\hline $\mathrm{H} 10-\mathrm{H} 1 \mathrm{I}$ & Disorders of conjunctiva & $1.0 \%$ \\
\hline $\mathrm{H} 15-\mathrm{H} 22$ & Disorders of sclera, cornea, iris and ciliary body & $62.3 \%$ \\
\hline $\mathrm{H} 25-\mathrm{H} 28$ & Disorders of the lens & $1.9 \%$ \\
\hline $\mathrm{H} 30-\mathrm{H} 36$ & Disorders of choroid and retina & $3.3 \%$ \\
\hline $\mathrm{H} 40-\mathrm{H} 42$ & Glaucoma & $1.0 \%$ \\
\hline $\mathrm{H} 43-\mathrm{H} 44$ & Disorders of vitreous body and globe & $0.4 \%$ \\
\hline $\mathrm{H} 46-\mathrm{H} 47$ & Disorders of optic nerve and visual pathways & $2.7 \%$ \\
\hline $\mathrm{H} 49-\mathrm{H} 52$ & Disorders of ocular muscles, binocular movement, accommodation and refraction \\
\hline $\mathrm{H} 53-\mathrm{H} 54$ & Visual disturbances and blindness & $1.2 \%$ \\
\hline $\mathrm{H} 55-\mathrm{H} 57$ & Other disorders of eye and adnexa & $0.4 \%$ \\
\hline $\mathrm{H} 59-\mathrm{H} 59$ & Intraoperative and post procedural complications and disorders of eye and adnexa, not & \\
\hline
\end{tabular}

\section{Hospital Admission Rate by Age Group}

The majority of hospital admissions were found to be higher in older age groups, except for disorders of the optic nerve and visual pathways, and disorders of ocular muscles, binocular movement, accommodation and refraction, which were more prevalent among the younger age groups (Figure 5).

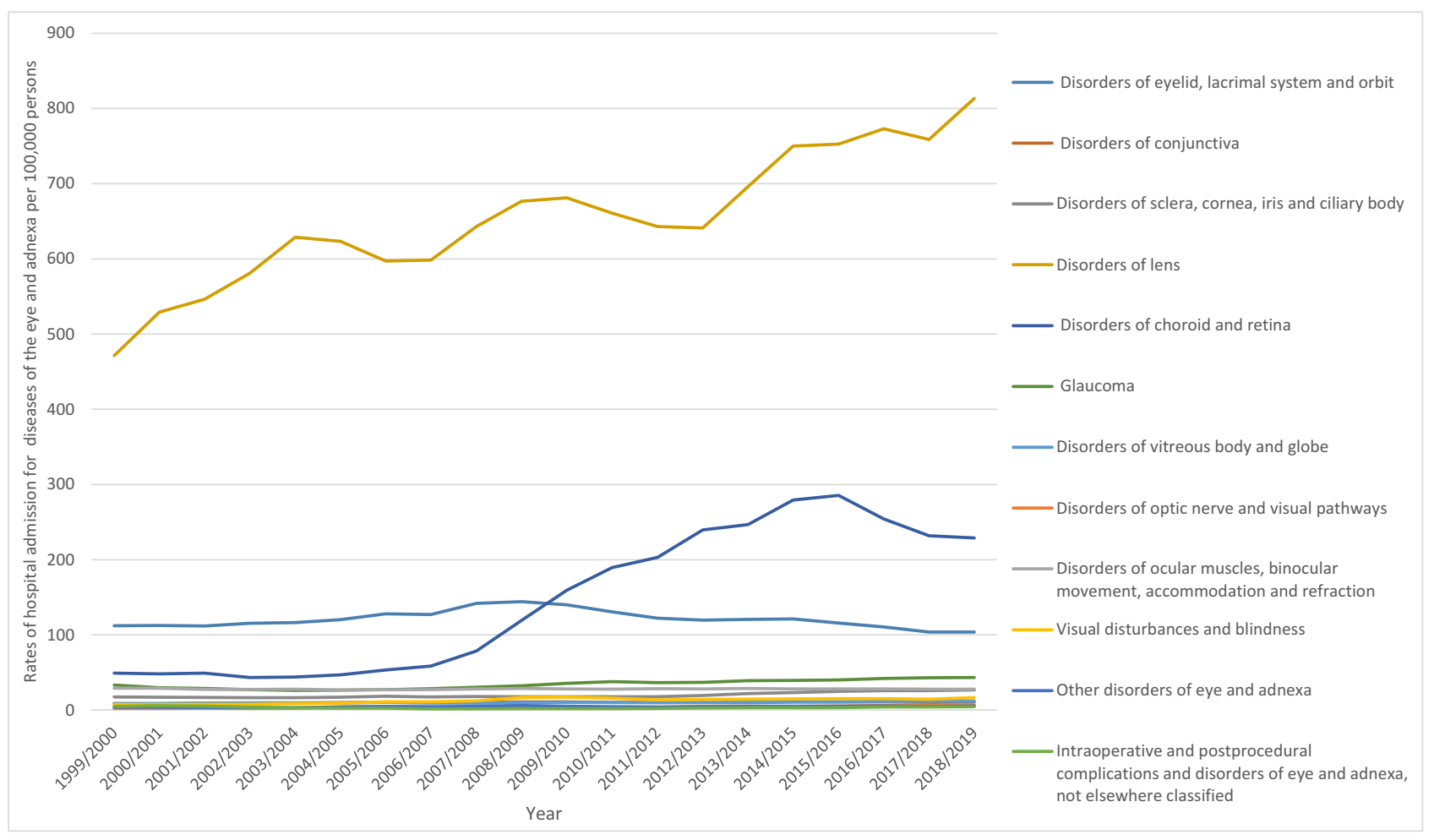

Figure I Hospital admission rates in England and Wales stratified by type between 1999 and 2019. 
Table 2 Percentage Change in the Hospital Admission Rates for Diseases of the Eye and Adnexa

\begin{tabular}{|c|c|c|c|}
\hline Diseases & $\begin{array}{c}\text { Rate of Diseases in } \\
1999 \text { per } 100,000 \text { Persons } \\
(95 \% \mathrm{Cl})\end{array}$ & $\begin{array}{c}\text { Rate of Diseases in } \\
2019 \text { per } 100,000 \text { Persons } \\
(95 \% \mathrm{Cl})\end{array}$ & $\begin{array}{l}\text { Percentage Change } \\
\text { from 1999-2019 }\end{array}$ \\
\hline Disorders of eyelid, lacrimal system and orbit & II 2.29 (III.38-II3.19) & $103.69(102.88-104.51)$ & $-7.7 \%$ \\
\hline Disorders of conjunctiva & $8.75(8.50-9.01)$ & $10.74(10.47-11.00)$ & $22.7 \%$ \\
\hline Disorders of sclera, cornea, iris and ciliary body & $17.36(\mid 7.01-17.72)$ & $26.84(26.42-27.26)$ & $54.6 \%$ \\
\hline Disorders of lens & $471.22(469.37-473.08)$ & $813.25(8|0.97-8| 5.53)$ & $72.6 \%$ \\
\hline Disorders of choroid and retina & $49.23(48.63-49.83)$ & $228.82(227.6 \mathrm{I}-230.04)$ & $364.8 \%$ \\
\hline Glaucoma & $33.15(32.66-33.65)$ & $43.25(42.72-43.77)$ & $30.4 \%$ \\
\hline Disorders of vitreous body and globe & $8.34(8.09-8.59)$ & $11.80(11.53-12.08)$ & $41.5 \%$ \\
\hline Disorders of optic nerve and visual pathways & $2.32(2.19-2.45)$ & $6.71(6.50-6.92)$ & $189.2 \%$ \\
\hline $\begin{array}{l}\text { Disorders of ocular muscles, binocular movement, } \\
\text { accommodation and refraction }\end{array}$ & $28.98(28.52-29.45)$ & $27.80(27.38-28.22)$ & $-4.1 \%$ \\
\hline Visual disturbances and blindness & $7.38(7.15-7.61)$ & $16.58(16.25-16.91)$ & $124.7 \%$ \\
\hline Other disorders of eye and adnexa & $3.76(3.59-3.93)$ & $5.39(5.21-5.58)$ & $43.5 \%$ \\
\hline $\begin{array}{l}\text { Intraoperative and postprocedural complications and } \\
\text { disorders of eye and adnexa, not elsewhere classified }\end{array}$ & $4.98(4.79-5.17)$ & $4.68(4.50-4.85)$ & $-6.1 \%$ \\
\hline
\end{tabular}

\section{Hospital Admission Stratified by Type of Admission}

Around half the reported number of admissions for diseases of the eye and adnexa was "regular admission that involved inpatients treatment" (Figure 6). The total annual rate for diseases of the eye and adnexa admission, emergency admission, waiting list, and day case increased by $72.4 \%, 16.0 \%, 63.0 \%$, and 1.23 -fold, respectively (Figure 7). The total annual number for diseases of the eye and adnexa admission, emergency admission, waiting list, and day case increased by $96.5 \%, 32.3 \%, 85.8 \%$, and 1.55 -fold, respectively (Table 3 ).

\section{Discussion}

To the best of our knowledge, this is the first study that has investigated the trends of hospital admissions concerning the diseases of the eye and adnexa in the UK in the last two decades. The current study found a significant increase in the rate of hospital admissions related to diseases of the eye and adnexa in England and Wales; an increase in hospital admission rate by $73.8 \%$, with an average increase of $3.7 \%$ per year during the past two decades. This significant increase in hospital admission rate can be attributed to the increased population resulting from improved life expectancy in both sexes and high average annual migration rates (approximately $0.67 \%$ per year from 2005 to 2020 ). ${ }^{24}$ In addition, the increasing awareness among the UK population of eye health problems, the availability of advanced diagnostic methods, and the existence of screening programmes play an important role in increasing the rate of hospital admissions. $^{25-27}$

For example, the number of all hospital admissions in England was 16.2 million between 2015 and 2016, increasing by 30\% from 12.7 million ten years before. The Hospital Admitted Patient Care Activity, 2015-16 report revealed that the largest number of hospital admissions (around 1.3 million admissions between 2015 and 2016) was observed in people aged 65 to 69 . The average age of hospitalised patients has also been rising steadily over the last years. The number of admissions increased slightly from 5.8 million to 6.3 million from 2005 to 2016, less than $9 \%$, in patients aged 44 and under, while it increased significantly from 6.9 million to 9.9 million by nearly $44 \%$ in patients aged 45 and above. Over the same period, the population grew by $8 \%$, at a much lower rate than the hospital admission rate $(30 \%)$. 


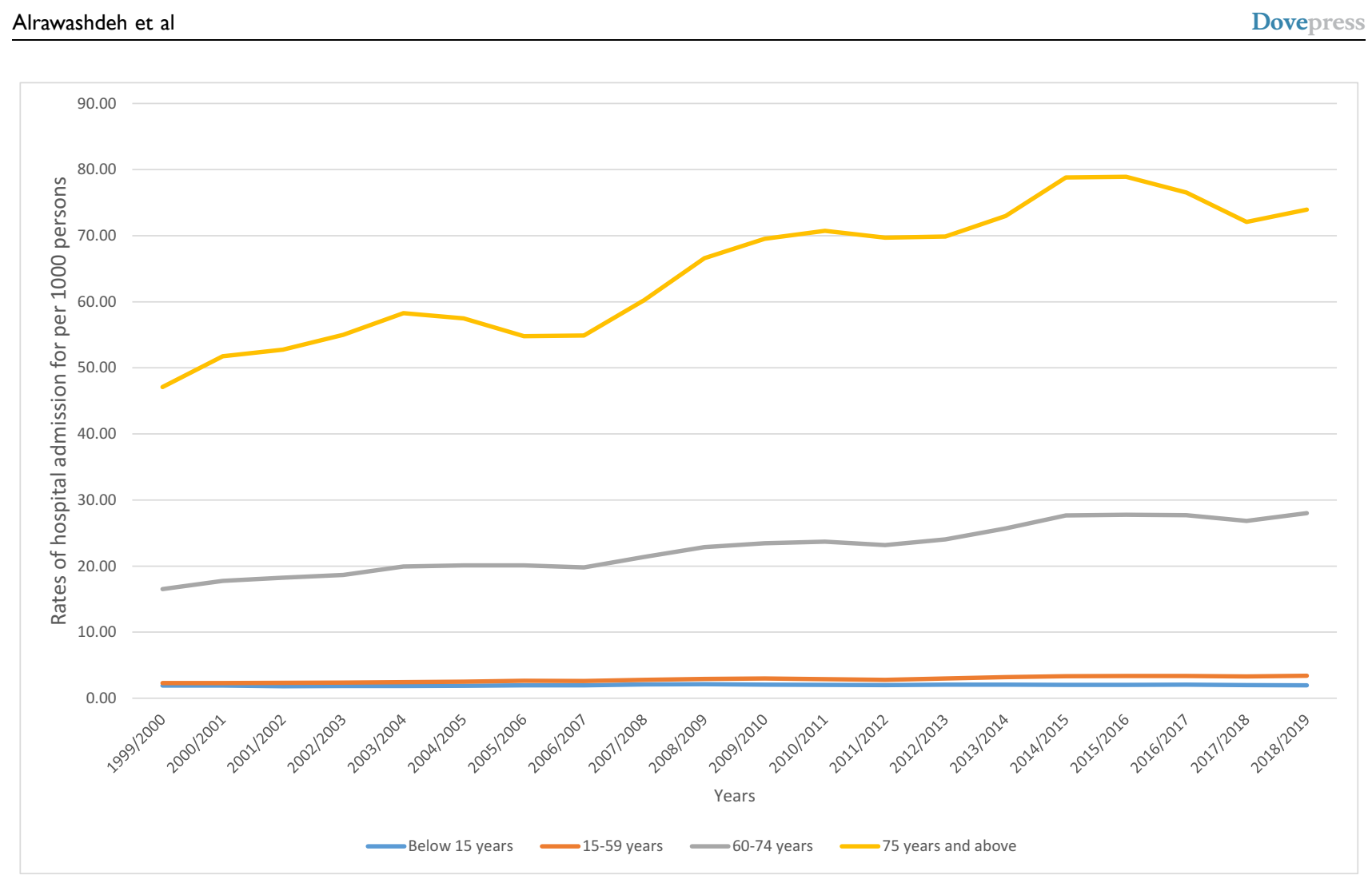

Figure 2 Overall rates of hospital admission stratified by age group.

Hospital admissions that needed interventions increased by $56 \%$, from 6.8 million to 10.6 million between 2005 and $2016^{28}$

In the UK, the number of females has been greater than the number of males over the last 70 years (in 2020, the estimated population by gender was approximately 34 million females and 33 million males). Life expectancy was also higher in females than males between 1981 and 2019 with low levels of improvement in life expectancy in males at limited periods. For example, from 2017 to 2019, life expectancy at birth was 79.4 and 83.1 years for males and females, respectively. At age 65 years, life expectancy was 18.8 and 21.1 years for males and females, respectively. The larger female population and the higher life expectancy in females put women at greater risk for age-related diseases than males. ${ }^{24}$ These demographic statistics explain the higher percentage $(56.9 \%)$ of total number of hospital admissions among females over the last two decades in England and Wales.

Our study revealed a $91.2 \%$ and $63.2 \%$ increase in the hospital admission rate among males and females in England and Wales in the last two decades, respectively. The higher increase in hospital admission rate among males can be attributed to the increased male to female ratio (the number of male births per one female birth) from 92.61 to 97.67 males per 100 females from 1950 to 2020 , with an average annual increase of $0.38 \%{ }^{3}$ Increased life expectancy among males has also contributed to this high rate.

The most common causes of hospital admissions for diseases of the eye and adnexa were lens disorders (62.3\%), followed by choroid and retina disorders (14.2\%), and eyelid, lacrimal system, and orbit disorders (11.5\%). This is related to the increasing number of people who have developed these diseases over the last decade in the UK. According to the Royal National Institute of Blind People (RNIB), in the UK, about 33,462,473, 25,332,332, and 54,876,508 people were at risk of having cataract, age-related macular degeneration (AMD) (early AMD, intermediate AMD, dry AMD, and wet AMD), and diabetic retinopathy (DRP) (background DRP, non-proliferative DRP, proliferative DRP, and diabetic maculopathy) in 2020, respectively. The estimated number of people who will experience partial sight loss and blindness due to cataracts is expected to reach 248,504 and 32,750 in 2020 , respectively. The yearly cataract surgery load is expected to reach 473,944 in $2020 .{ }^{29}$ The estimated number of people who will have wet AMD is expected to reach 


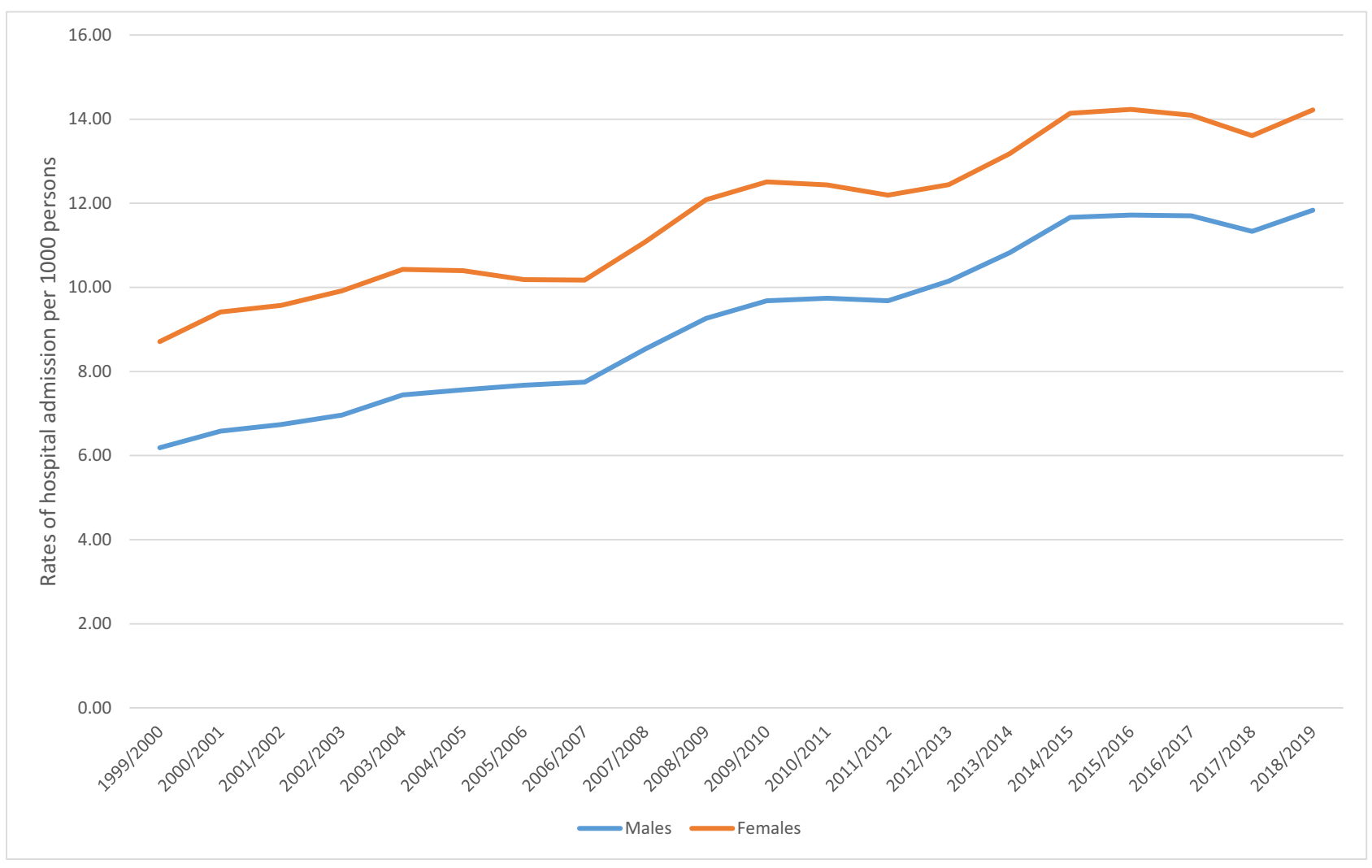

Figure 3 Overall rates of hospital admission stratified by gender.

515,509 in 2020, up from 414,561 in 2010. ${ }^{29}$ In England and Wales, where AMD is the leading cause of visual impairment, ${ }^{30}$ the estimated number of people who will have wet AMD is expected to reach 458,617, representing $89 \%$ of the total number of expected cases in the UK. ${ }^{29}$

By 2020 in the UK, it is expected that there will be more people who have background DRP (from 748,209 people in 2010 to 938,448 by 2020 (833,410 in England and Wales)) and diabetic maculopathy (from 187,842 in 2010 to 235,602 by 2020 (209,232 in England and Wales)) than previously. ${ }^{29}$ Disorders of the eyelid, lacrimal system and orbit are common in the UK population. This can be attributed to the aging population, who are more susceptible to senile ptosis, lacrimal, and orbital disorders. Thyroid eye disease (TED), which is the most common cause of proptosis and orbital inflammation in adults worldwide, ${ }^{31}$ also occurs frequently in the UK (about 300,000 people in the UK have TED). ${ }^{32}$

In this study, we found that the highest increase in hospital admission rate was due to disorders of the choroid and retina. This can be correlated to the increased number of admissions due to surgically treated retinal diseases such as retinal detachment. In 2018, Madi and Keller found that the hospital admission frequency due to retinal detachment was increased significantly between 2000 and 2018, particularly for rhegmatogenous retinal detachment. They attributed this to the increased rates of cataract surgeries, myopia, recurrent retinal detachment, and increased longevity, which increased disease incidence among the UK population. ${ }^{33}$ The high incidence of DRP and wet AMD in the UK might affect the hospital admission rate in our study. Vitreoretinal surgeries for managing the complications of DRP, such as vitreous hemorrhage and tractional retinal detachment, could contribute significantly to this increase. Patients with DRP, wet AMD, or other retinal vascular diseases treated with intravitreal injections of anti-vascular endothelial growth factor (anti-VEGF) drugs receive their therapy mainly at outpatient clinics (clean rooms) or, sometimes, at operating rooms. Thus, this might not realistically reflect the participation of these conditions in increasing the hospital admission rate despite the significant increase in the number of injections used in the last decade. Bevacizumab, ranibizumab, and aflibercept are anti-VGEF drugs used for DRP and wet AMD treatment. In some patients, laser and photodynamic therapies can be used with anti-VGEF treatment. ${ }^{34-36}$ A study carried out at Moorfields Eye Hospital, a large tertiary 

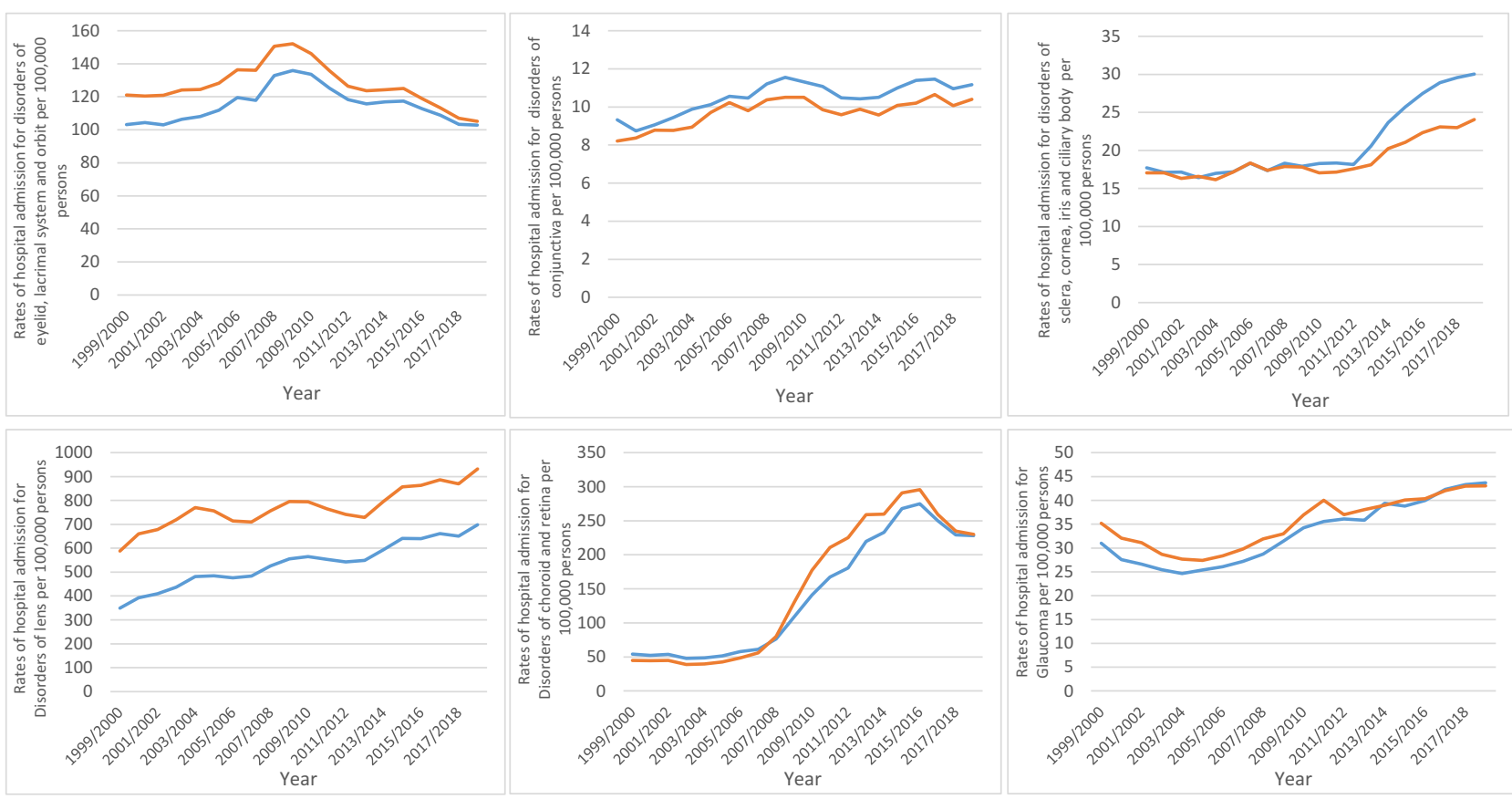

- Males _Females
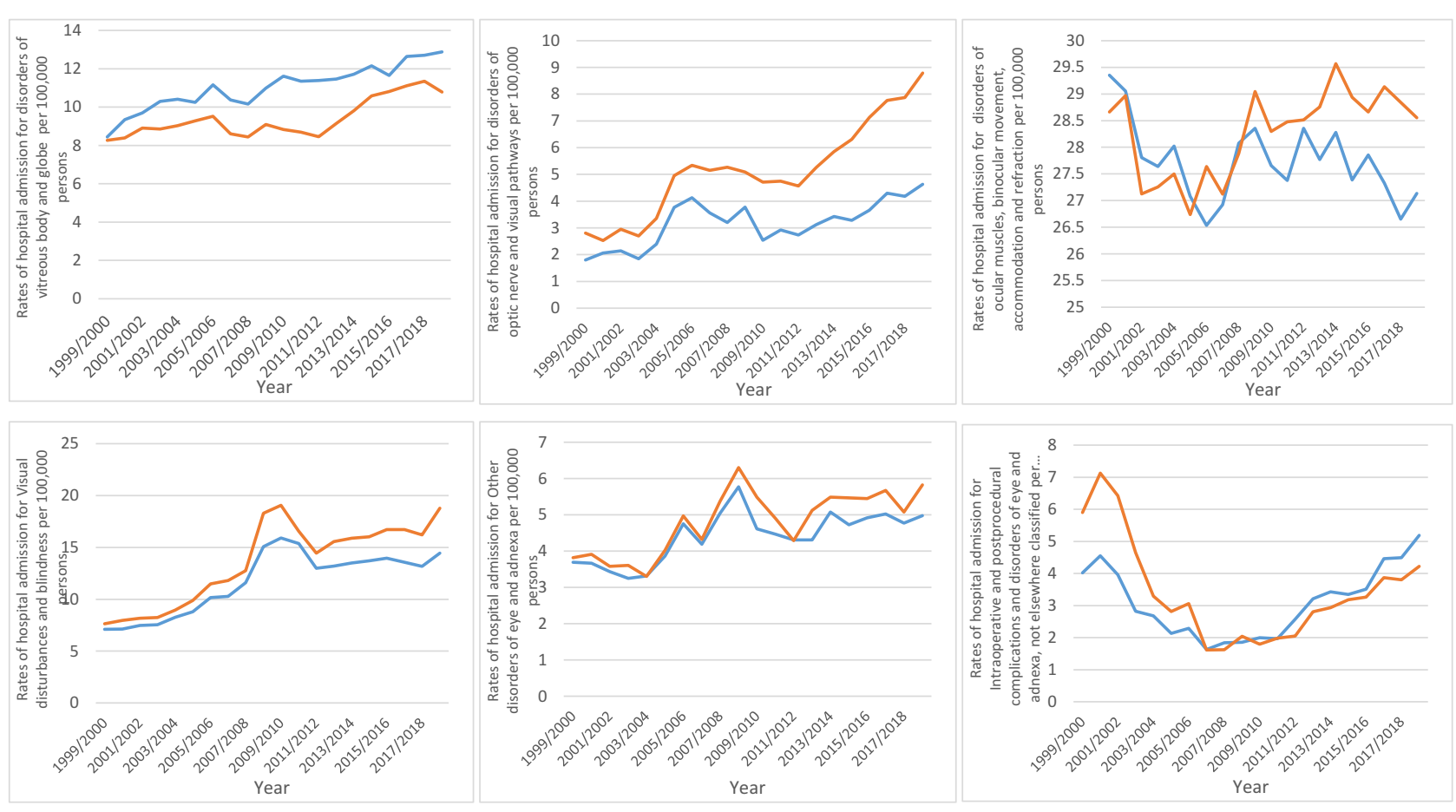

-Males _Females

Figure 4 Rates of hospital admission stratified by type and gender.

referral centre in the UK, found that the number of intravitreal injections had increased about 11-fold between 2009 and 2019. A total of 44,924 injections were given in 2019 , of which $87 \%$ were Aflibercept. The majority of injections were delivered for wet AMD treatment. ${ }^{37}$ The second-highest rate was observed in disorders of the optic nerve and visual 

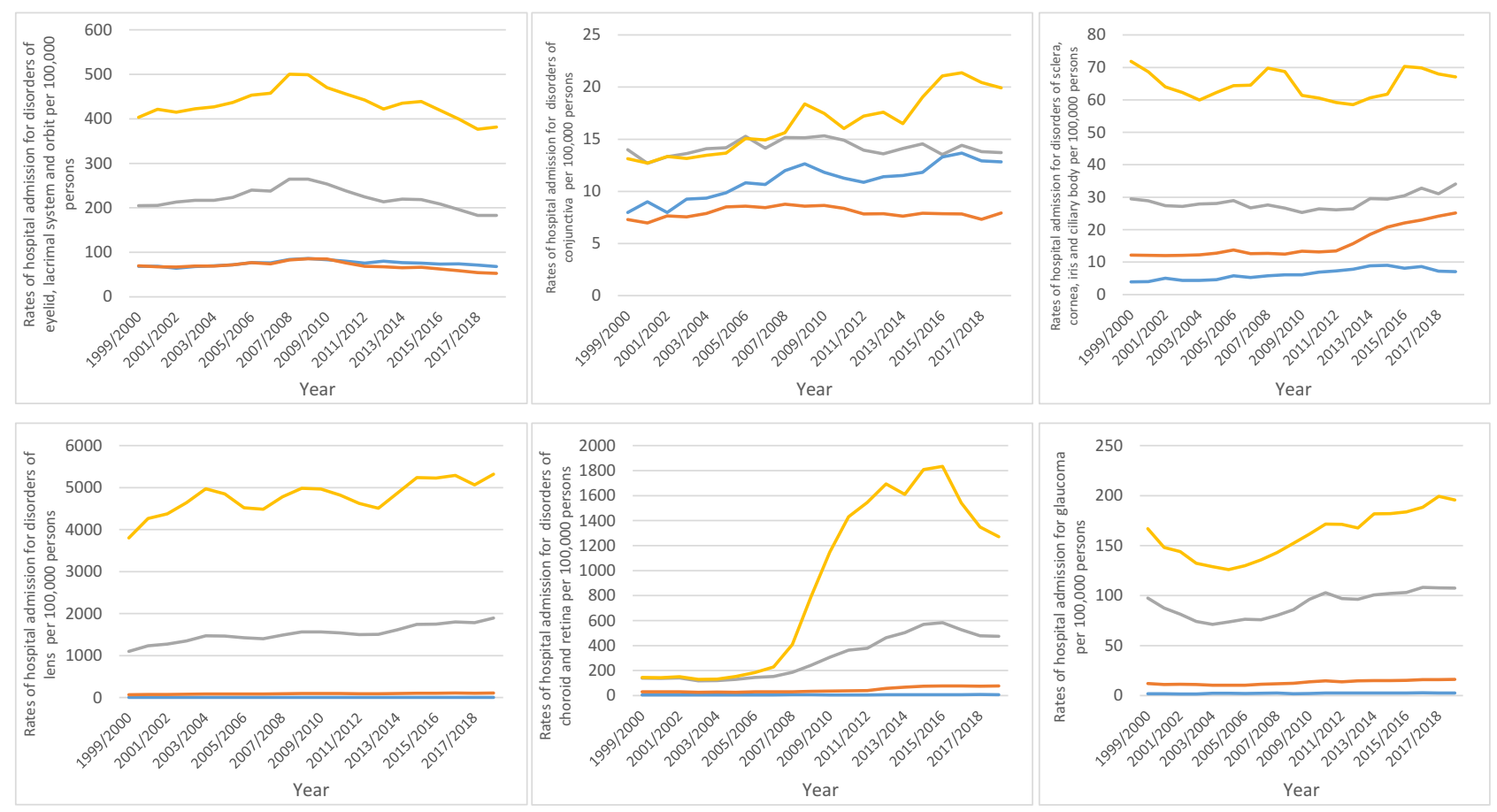

$\begin{array}{ll}\text { — Age group (Below } 15 \text { years) } & \text { - Age group (15-59 years) } \\ \text { Age group (60-74 years) } & \text { - Age group (75 years and above) }\end{array}$
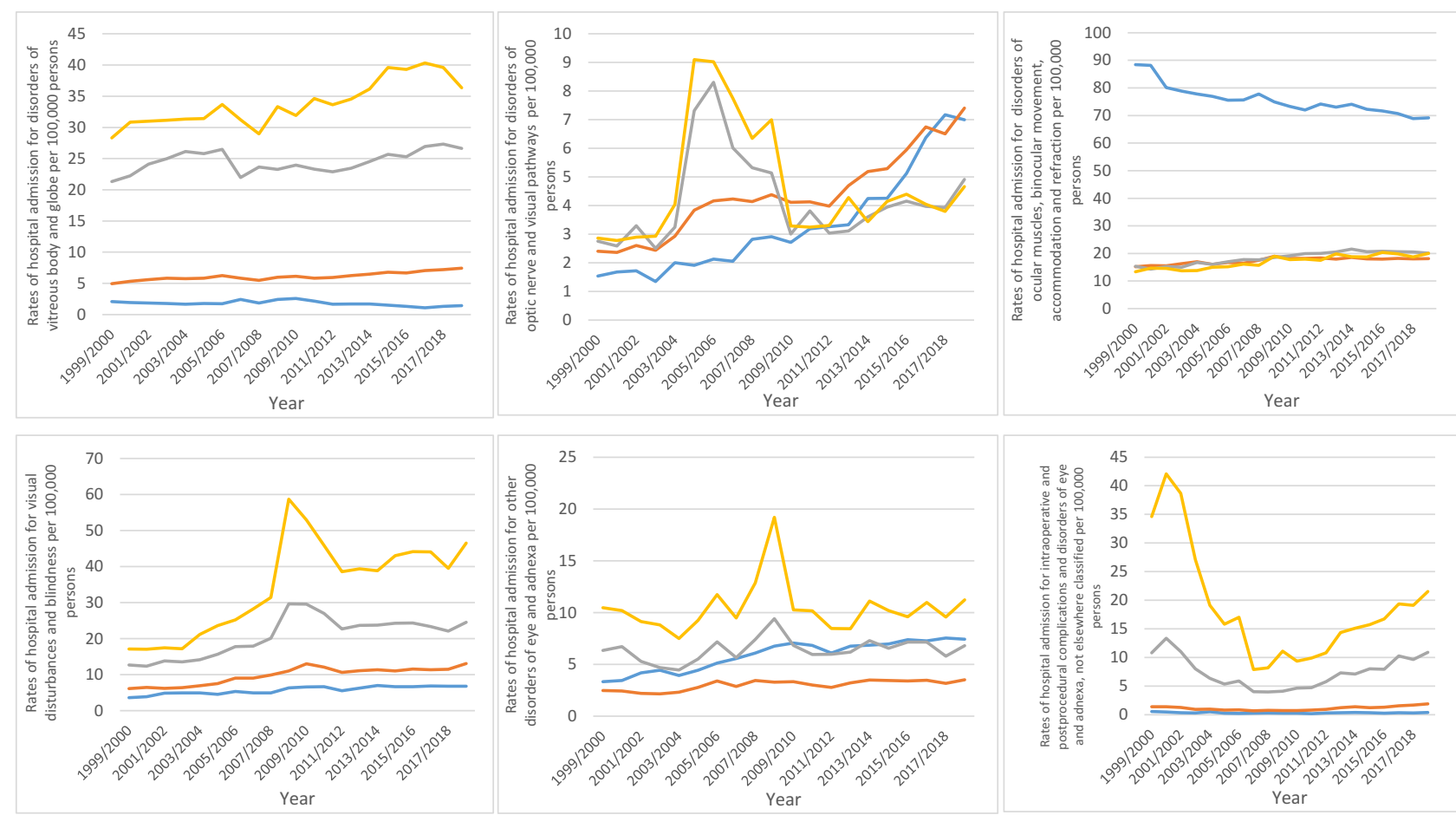

$\begin{array}{ll}\text { — Age group (Below } 15 \text { years) } & \text { - Age group (15-59 years) } \\ \text { - Age group (60-74 years) } & \text { - Age group (75 years and above) }\end{array}$

Figure 5 Rates of hospital admission stratified by type and age. 


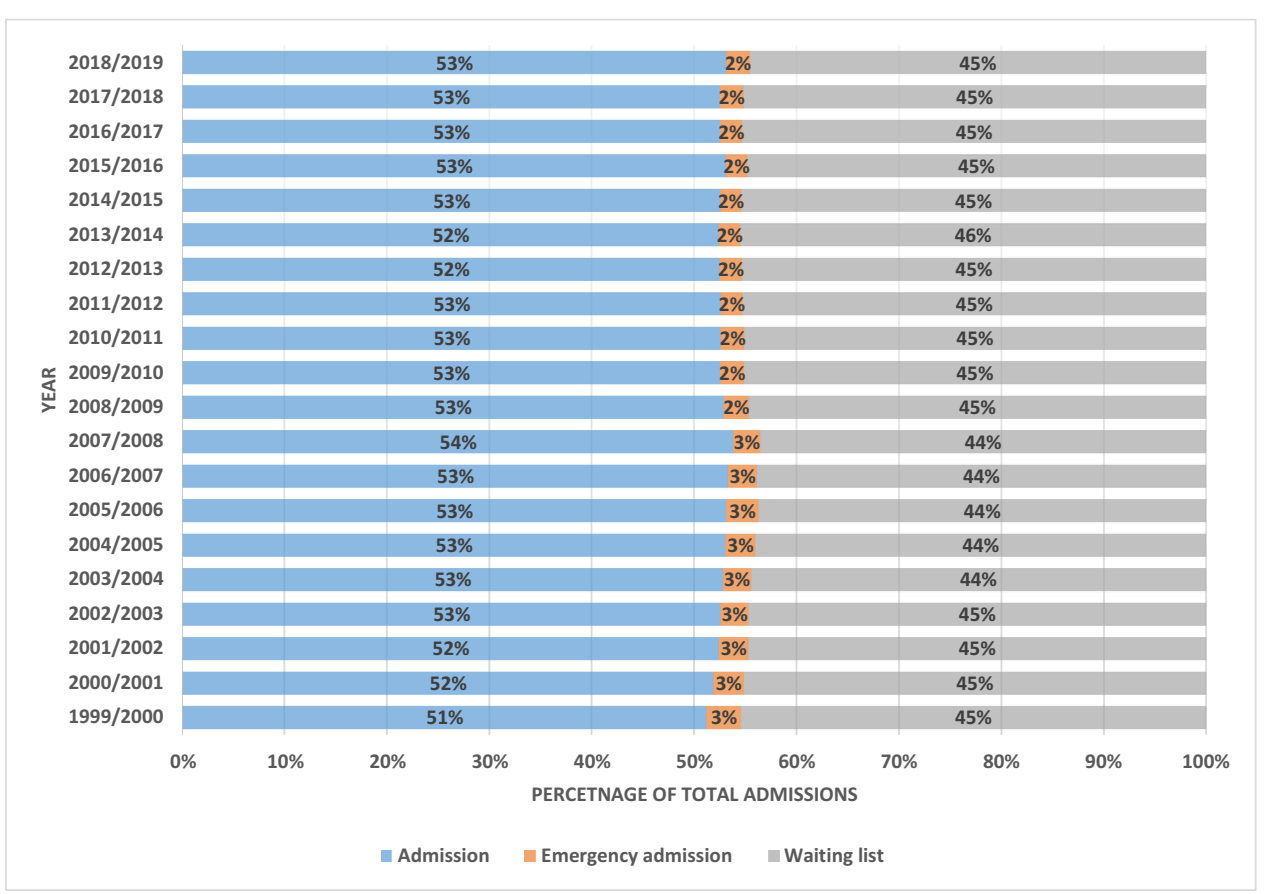

Figure 6 Percentage of each admission type for diseases of the eye and adnexa from total number of reported admissions per year.

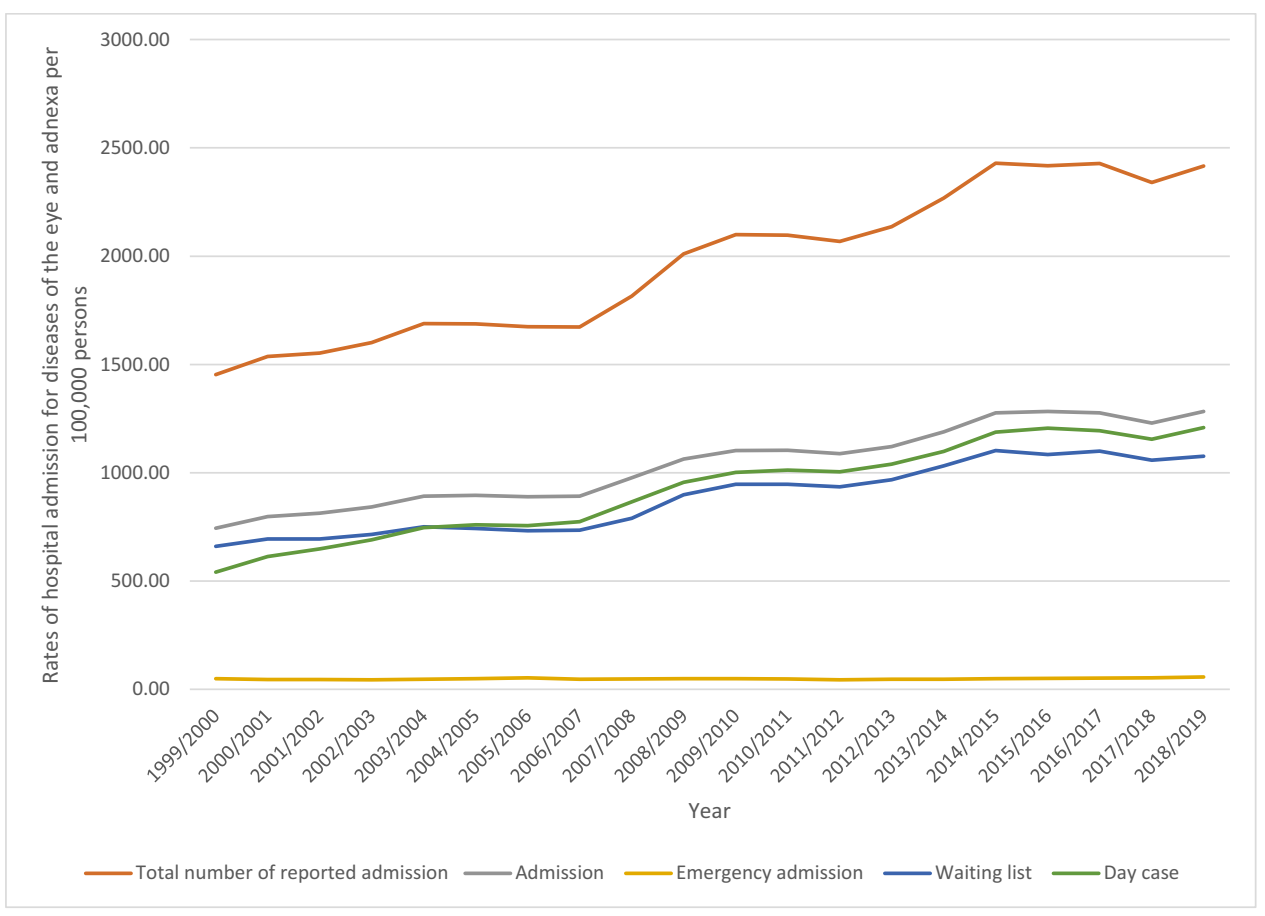

Figure 7 Hospital admission rates due to diseases of the eye and adnexa in stratified by admission type between 1999 and 2019.

pathways, which can be linked to the aging population in the UK, who are more prone to stroke and optic nerve diseases, such as anterior ischemic optic neuropathy and giant cell arteritis. ${ }^{38-40}$

Gender and age were significant factors that contributed to the increased hospital admission rate due to specific types of diseases of the eye and adnexa. Marked fluctuations in females' hormones during menstruation, pregnancy, and menopause can protect, induce, or exaggerate many ocular conditions. This hormonal effect is related to the presence of 
Table 3 Hospital Admission Numbers for Diseases of the Eye and Adnexa Stratified by Type of Admission

\begin{tabular}{|c|c|c|c|c|c|c|c|c|c|c|c|c|c|c|c|}
\hline & \multirow{2}{*}{\multicolumn{3}{|c|}{$\begin{array}{c}\text { Total Number of Reported } \\
\text { Admissions }\end{array}$}} & \multicolumn{9}{|c|}{ Type of Admission } & \multirow{2}{*}{\multicolumn{3}{|c|}{$\begin{array}{l}\text { Day Case (Elective Inpatients } \\
\text { Who Have Been Admitted for } \\
\text { Treatment Just for the Day) }\end{array}$}} \\
\hline & & & & \multicolumn{3}{|c|}{$\begin{array}{c}\text { Admission (Involving Inpatient } \\
\text { Treatment) }\end{array}$} & \multicolumn{3}{|c|}{ Emergency Admission } & \multicolumn{3}{|c|}{$\begin{array}{l}\text { Waiting List (Indicating Elective } \\
\text { Admission Method) }\end{array}$} & & & \\
\hline & $\begin{array}{l}\text { England and } \\
\text { Wales }\end{array}$ & England & Wales & $\begin{array}{l}\text { England and } \\
\text { Wales }\end{array}$ & England & Wales & $\begin{array}{l}\text { England and } \\
\text { Wales }\end{array}$ & England & Wales & $\begin{array}{l}\text { England and } \\
\text { Wales }\end{array}$ & England & Wales & $\begin{array}{l}\text { England and } \\
\text { Wales }\end{array}$ & England & Wales \\
\hline 1999/2000 & 757,707 & 713,664 & 44,043 & 388,141 & 362,378 & 25,763 & 25,368 & 23,926 & 1442 & 344,198 & 327,360 & 16,838 & 282,060 & 265,475 & 16,585 \\
\hline $2000 / 2001$ & 805,055 & 751,233 & 53,822 & 417,696 & 386,577 & 31,119 & 23,836 & 22,489 & 1347 & 363,523 & 342,167 & 21,356 & 321,195 & 298,274 & 22,921 \\
\hline $2001 / 2002$ & 815,994 & 759,332 & 56,662 & 427,600 & 394,655 & 32,945 & 23,609 & 22,310 & 1299 & 364,785 & 342,367 & 22,418 & 340,695 & 315,219 & 25,476 \\
\hline $2002 / 2003$ & 845,524 & 795,743 & 49,781 & 444,484 & 416,937 & 27,547 & 23,298 & 21,972 & 1326 & 377,742 & 356,834 & 20,908 & 364,654 & 342,721 & 21,933 \\
\hline $2003 / 2004$ & 895,586 & 847,601 & 47,985 & 472,925 & 446,070 & 26,855 & 24,599 & 23,321 & 1278 & 398,062 & 378,210 & 19,852 & 396,153 & 373,873 & 22,280 \\
\hline $2004 / 2005$ & 901,470 & 854,670 & 46,800 & 478,250 & $452,4 \mid 4$ & 25,836 & 26,510 & 25,269 & $|24|$ & 396,710 & 376,987 & 19,723 & 405,661 & 383,933 & 21,728 \\
\hline $2005 / 2006$ & 899,285 & 847,703 & 51,582 & 477,780 & 450,149 & 27,631 & 28,447 & 27,158 & 1289 & 393,058 & 370,396 & 22,662 & 406,214 & 382,160 & 24,054 \\
\hline $2006 / 2007$ & 905,075 & 850,899 & 54,176 & 482,534 & 453,417 & 29,117 & 25,449 & 24,160 & 1289 & 397,092 & 373,322 & 23,770 & 418,544 & 392,757 & 25,787 \\
\hline $2007 / 2008$ & 988,620 & 932,838 & 55,782 & 532,128 & 501,582 & 30,546 & 26,060 & 24,698 & 1362 & 430,432 & 406,558 & 23,874 & 471,524 & 444,229 & 27,295 \\
\hline $2008 / 2009$ & I,I02,204 & $\mathrm{I}, 037,140$ & 65,064 & 582,706 & 549,528 & 33,178 & 27,294 & 25,926 & 1368 & 492,204 & 461,686 & 30,518 & 524,000 & 493,910 & 30,090 \\
\hline $2009 / 2010$ & $1,159,512$ & $1,095,902$ & 63,610 & 609,185 & 576,661 & 32,524 & 27,041 & 25,661 & 1380 & 523,286 & 493,580 & 29,706 & 553,335 & 523,831 & 29,504 \\
\hline $2010 / 2011$ & I,I 178,099 & I,II5,268 & 62,831 & 619,816 & 587,598 & 32,218 & 26,705 & 25,236 & 1469 & 531,578 & 502,434 & 29,144 & 568,465 & 539,187 & 29,278 \\
\hline $2011 / 2012$ & I,169,583 & I, 105,866 & 63,717 & 615,278 & 583,131 & 32,147 & 25,000 & 23,642 & 1358 & 529,305 & 499,093 & 30,212 & 568,519 & 538,972 & 29,547 \\
\hline $2012 / 2013$ & $1,216,695$ & $\mathrm{I}, 154,26 \mathrm{I}$ & 62,434 & 638,663 & 607,134 & 31,529 & 26,612 & 25,133 & 1479 & 551,420 & 521,994 & 29,426 & 592,246 & 563,464 & 28,782 \\
\hline $2013 / 2014$ & I,302,132 & I,234,849 & 67,283 & 682,536 & 648,510 & 34,026 & 27,091 & 25,515 & 1576 & 592,505 & 560,824 & $31,68 \mid$ & 630,597 & 599,604 & 30,993 \\
\hline $2014 / 2015$ & I,406,062 & $1,338,079$ & 67,983 & 739,216 & 704,913 & 34,303 & $28,48 \mid$ & 26,732 & 1749 & 638,365 & 606,434 & 31,931 & 687,430 & 656,244 & 31,186 \\
\hline $2015 / 2016$ & I,4II,300 & $1,340,125$ & 71,175 & 749,221 & 713,287 & 35,934 & 29,327 & 27,534 & 1793 & 632,752 & 599,304 & 33,448 & 703,666 & 670,871 & 32,795 \\
\hline $2016 / 2017$ & I,426,645 & $\mathrm{I}, 35 \mathrm{I}, 746$ & 74,899 & 749,659 & 711,723 & 37,936 & 30,551 & 28,689 & 1862 & 646,435 & 611,334 & 35,101 & 701,324 & 666,676 & 34,648 \\
\hline $2017 / 2018$ & I,383,807 & $1,307,710$ & 76,097 & 726,697 & 688,212 & 38,485 & 31,797 & 30,061 & 1736 & 625,313 & 589,437 & 35,876 & 682,692 & 647,403 & 35,289 \\
\hline $2018 / 2019$ & $1,435,924$ & $1,353,430$ & 82,494 & 762,707 & 720,870 & 41,837 & 33,556 & 31,628 & 1928 & 639,661 & 600,932 & 38,729 & 718,249 & 679,937 & 38,312 \\
\hline$\%$ Change & $89.5 \%$ & $89.6 \%$ & $87.3 \%$ & $96.5 \%$ & 98.9\% & $62.4 \%$ & $32.3 \%$ & $32.2 \%$ & $33.7 \%$ & $85.8 \%$ & $83.6 \%$ & $130.0 \%$ & $154.6 \%$ & $156.1 \%$ & $131.0 \%$ \\
\hline
\end{tabular}


sex hormone receptors in the eyes. For example, uveitis symptoms were found to be exacerbated by menstruation and stabilised during pregnancy, and oestrogen was found to expose women to a higher risk for progression of diabetic retinopathy. ${ }^{41}$ Androgens in males also affect the eye and may be the cause of increasing prevalence of some ocular disorders in men. ${ }^{42}$

We found that the admission rate for some disorders was higher among females, including lens disorders, choroidal and retinal disorders, optic nerve and visual pathways disorders, eyelid, orbit, and lacrimal systems disorders, and visual disturbance and blindness. Female gender is considered a risk factor for many ocular diseases, such as cataracts, glaucoma, wet AMD, DRP, optic neuritis, thyroid eye disease, and autoimmune diseases. ${ }^{1,41-43}$ In both developed and developing countries, two out of three blind people are women. ${ }^{42}$ Concerning age, we found that the rate of admissions for disorders of ocular muscles, binocular movement, accommodation and refraction was significantly higher among people aged below 15 (children and teenagers) since these disorders are more frequent among this age group.

All types of admissions increased during the past two decades for diseases of the eye and adnexa whether regular admissions, emergency admissions or waiting list admissions. This indicates a better health-care system and early detection and diagnosis of diseases in the clinical practice. However, the rise in emergency admission is also related to the progression of the disease, and may reflect the severity of the disease which require frequent hospitalisation and diagnostic or therapeutic interventions.

To the best of our knowledge, this is the first study to explore trends in the rates of hospital admission due to diseases of the eye and adnexa worldwide and in England and Wales specifically without restricting the study to specific inclusion/ exclusion criteria. The study was a population study at the national level. Our study provided detailed hospital admission rate for all diseases of the eye and adnexa stratified by age and gender giving a clear imagination about the hospitalisation profile for this group of patients for a period of 20 years. This study has some limitations. First, for each ICD-10 code range, we were unable to specifically identify which eye problems had the greatest impact on the hospital admission rate. Second, due to the nature of data provided by these databases we were unable to access data on the patient level to identify other risk factors associated with eye problems, such as the presence of comorbidities (such as diabetes mellitus) or other factors associated with eye problems. The reported hospital admission data in this study include emergency and elective admission, therefore, findings should be interpreted carefully as this might have led to overestimation of the presented admission rate. Another limitation is the impact of time-trend analysis on the study findings, as with the changing in indication for hospital admission (such as increasing trend of one day surgery), the proportion of some ocular disorders might not reflect the real intervention that had been performed.

\section{Conclusion}

Hospital admissions related to eye and adnexa disorders are common in the UK. There are clear gender and age roles in the epidemiology of hospital admissions related to eye and adnexa disorders. Further observational studies are warranted to identify other risk factors for these important causes of hospitalisation.

\section{Data Sharing Statement}

Publicly available datasets were analyzed in this study. This data can be found here: http://http//content.digital.nhs.uk/ hes, http://www.infoandstats.wales.nhs.uk/page.cfm?pid=41010\&orgid=869.

\section{Ethics Approval and Informed Consent}

The research ethics committee of the Faculty of Pharmacy at Isra University approved the study protocol (SREC/21/11/ 014). Hospital admissions, mortality, and population data are publicly available as de-identified data. Therefore, it was considered an exempt category.

\section{Disclosure}

The authors declare no conflicts of interest in this work. 


\section{References}

1. Alrawashdeh HM. Cataract and healthy diet, an ounce of prevention is worth a pound of cure - a mini-review. J Food Nutr Health. 2020;1(1):1-3. doi: $10.47275 / 2692-5222-105$

2. Partyka O, Wysocki M. Epidemiology of eye diseases and infrastructure of ophthalmology in Poland. Przegl Epidemiol. 2015;69(4):773-777.

3. Office for National Statistics (ONS). Population estimates; 2021. Available from: https://www.ons.gov.uk/peoplepopulationandcommunity/popula tionandmigration/populationestimates/datasets/populationestimatesforukenglandandwalesscotlandandnorthernireland. Accessed January $13,2021$.

4. Worldometer. Countries in the world by population (2021); 2021. Available from: https://www.worldometers.info/world-population/population-bycountry/. Accessed January 25, 2021.

5. Public Health England. How local global burden of disease data can help shift the focus for the NHS; 2021. Available from: https://publichealth matters.blog.gov.uk/2018/10/25/how-local-global-burden-of-disease-data-can-help-shift-the-focus-for-the-nhs/. Accessed January 27, 2021.

6. Laitinen A, Laatikainen L, Harkanen T, Koskinen S, Reunanen A, Aromaa A. Prevalence of major eye diseases and causes of visual impairment in the adult Finnish population: a nationwide population-based survey. Acta Ophthalmol. 2010;88(4):463-471. doi:10.1111/j.1755-3768.2009.01566.x

7. Costin BR, Perry JD. Ocular adnexal infections. Curr Ophthalmol Rep. 2014;2(3):124-128. doi:10.1007/s40135-014-0045-5

8. Orazi A, Foucar K, Knowles D, Weiss L. Neoplastic Hematopathology. 3rd ed. Philadelphia, USA: Lippincott Williams \& Wilkins; 2013.

9. Platnick J, Crum A, Soohoo S, Cedeño P, Johnson M. The globe: infection, inflammation, and systemic disease. Semin Ultrasound CT MR. 2011;32 (1):38-50. doi:10.1053/j.sult.2010.12.003

10. Vieira-Potter V, Karamichos D, Lee D. Ocular complications of diabetes and therapeutic approaches. Biomed Res Int. 2016;2016:1-14. doi:10.1155/ 2016/3801570

11. Alrawashdeh HM. An overview of diabetic retinopathy. Obes Diabetes Res. 2020;1(1):1-3. doi:10.47275/2692-0964-104

12. Smittenaar CR, Petersen KA, Stewart K, Moitt N. Cancer incidence and mortality projections in the UK until 2035. Br J Cancer. 2016;115 (9):1147-1155. doi:10.1038/bjc.2016.304

13. Jankowski R. What do hospital admission rates say about primary care? BMJ. 1999;319(7202):67-68. doi:10.1136/bmj.319.7202.67

14. Health and Social Care Information Centre (HSCIC). Hospital episode statistics; 2021. Available from: http://content.digital.nhs.uk/hes. Accessed January 13, 2021.

15. NHS Wales Informatics Service. Annual PEDW data tables; 2021. Available from: http://www.infoandstats.wales.nhs.uk/page.cfm?pid= 41010\&orgid=869. Accessed January 13, 2021.

16. Naser A, Wang Q, Wong L, et al. Hospital admissions due to dysglycaemia and prescriptions of antidiabetic medications in England and Wales: an Ecological Study. Diabetes Ther. 2018;9(1):153-163. doi:10.1007/s13300-017-0349-1

17. Tulloch J, Decraene V, Christley R, Radford A, Warner J, Vivancos R. Characteristics and patient pathways of Lyme disease patients: a retrospective analysis of hospital episode data in England and Wales (1998-2015). BMC Public Health. 2019;19(931):1-11. doi:10.1186/ s12889-019-7245-8

18. Hemmo SI, Naser AY, Alwafi H, et al. Hospital admissions due to ischemic heart diseases and prescriptions of cardiovascular diseases medications in England and Wales in the past two decades. Int J Environ Res Public Health. 2021;18(13):13. doi:10.3390/ijerph18137041

19. Naser AYA, Alrawashdeh HM, Alwafi H, et al. Hospital admission trends due to viral infections characterised by skin and mucous membrane lesions in the past two decades in England and Wales: an Ecological Study. Int J Environ Res Public Health. 2021;18(21):11649. doi:10.3390/ ijerph182111649

20. Naser AY, Mansour MM, Alanazi AFR, et al. Hospital admission trends due to respiratory diseases in England and Wales between 1999 and 2019 : an ecologic study. BMC Pulm Med. 2021;21(1):356. doi:10.1186/s12890-021-01736-8

21. Alanazi AFR, Naser AY, Pakan P, et al. Trends of hospital admissions due to congenital anomalies in England and Wales between 1999 and 2019 : an Ecological Study. Int J Environ Res Public Health. 2021;18:22. doi:10.3390/ijerph182211808

22. ICD10DATA.com. ICD-10-CM codes > H00-H59 diseases of the eye and adnexa; 2021. Available from: https://www.icd10data.com/ICD10CM/ Codes/H00-H59/H55-H57/H57-/H57.9. Accessed January 25, 2021.

23. NHS Wales Informatics Service. Data quality status report: admitted patient care data set; 2021. Available from: http://www.infoandstats.wales.nhs. uk/Documents/869/APC\%20DQ\%20Status\%20Report\%202015-16-v1.pdf. Accessed January 13, 2021.

24. World Data Atlas. The United Kingdom; 2021. Available from: https://knoema.com/atlas/United-Kingdom/topics/Demographics/Population. Accessed January 15, 2021.

25. Public Health England. NHS Diabetic Eye Screening Programme: Information for Health Professionals; 2021.

26. Brooke S. Eye health cannot be ignored; 2018. Available from: https://www.raconteur.net/healthcare/eye-health/national-eye-health-week/. Accessed February 19, 2021.

27. The Royal National Institute of Blind People. The state of the nation eye health 2017: a year in review; 2021. Available from: https://www.rnib.org. uk/sites/default/files/APDF\%20The\%20State\%20of\%20the\%20Nation\%20\%20Eye\%20Health\%202017\%20A\%20Year\%20in\%20Review.pdf. Accessed February 19, 2021.

28. National Health Services. Hospital admitted patient care activity, 2015-16; 2016. Available from: https://webarchive.nationalarchives.gov.uk/ 20180328130140/http://digital.nhs.uk/catalogue/PUB22378. Accessed February 16, 2021.

29. Minassian D, Reidy A. Future sight loss UK 2; 2009. Available from: https://www.rnib.org.uk/knowledge-and-research-hub/research-reports /general-research/future-sight-loss-uk-2. Accessed February 16, 2021.

30. Quartilho A, Simkiss P, Zekite A, Xing W, Wormald R, Bunce C. Leading causes of certifiable visual loss in England and Wales during the year ending 31 March 2013. Eye. 2016;30(4):602-607. doi:10.1038/eye.2015.288

31. Cockerham K, Chan S. Thyroid eye disease. Neurol Clin. 2010;28(3):729-755. doi:10.1016/j.ncl.2010.03.010

32. FlightforSight. Thyroid eye disease: what is it? 2015. Available from: https://www.fightforsight.org.uk/about-the-eye/a-z-eye-conditions/thyroideye-disease/. Accessed February 17, 2021.

33. Madi H, Keller J. Increasing frequency of hospital admissions for retinal detachment and vitreo-retinal surgery in England 2000-2018. Eye. 2021; published online ahead of print:1-5.

34. Meyer C, Holz F. Preclinical aspects of anti-VEGF agents for the treatment of wet AMD: ranibizumab and bevacizumab. Eye. 2011;25(6):661-672. doi:10.1038/eye.2011.66 
35. Sarireh FA, Alrawashdeh HM, Zubi KA, Salem KA. Intravitreal bevacizumab alone versus combined bevacizumab and macular grid laser photocoagulation in diffuse diabetic macular oedema. J Clin Diagn Res. 2020;14(11):NC05-NC09.

36. Thomas M, Mousa S, Mousa S. Comparative effectiveness of aflibercept for the treatment of patients with neovascular age-related macular degeneration. Clin Ophthalmol. 2013;7:495-501. doi:10.2147/OPTH.S29974

37. Chopra R, Preston G, Keenan T, et al. Intravitreal injections: past trends and future projections within a UK tertiary hospital. Eye. 2021:1-6. doi:10.1038/s41433-021-01646-3

38. Kermani T, Schäfer V, Crowson C, et al. Increase in age at onset of giant cell arteritis: a population-based study. Ann Rheum Dis. 2010;69 (4):780-781. doi:10.1136/ard.2009.111005

39. Miller N, Arnold A. Current concepts in the diagnosis, pathogenesis and management of nonarteritic anterior ischaemic optic neuropathy. Eye. 2015;29(1):65-79. doi:10.1038/eye.2014.144

40. Yousufuddin M, Young N. Aging and ischemic stroke. Aging. 2019;11(9):2542-2544. doi:10.18632/aging.101931

41. Kazama S, Kazama J, Ando N. Eye diseases in women. Fukushima J Med Sci. 2019;65(2):30-36. doi:10.5387/fms.2019-01

42. Zetterberg M. Age-related eye disease and gender. Maturitas. 2016;83:19-26. doi:10.1016/j.maturitas.2015.10.005

43. Eisner A. Sex, eyes, and vision: male/female distinctions in ophthalmic disorders. Curr Eye Res. 2015;40(2):96-101. doi:10.3109/ 02713683.2014 .975368

\section{Publish your work in this journal}

The International Journal of General Medicine is an international, peer-reviewed open-access journal that focuses on general and internal medicine, pathogenesis, epidemiology, diagnosis, monitoring and treatment protocols. The journal is characterized by the rapid reporting of reviews, original research and clinical studies across all disease areas. The manuscript management system is completely online and includes a very quick and fair peer-review system, which is all easy to use. Visit http://www.dovepress.com/testimonials.php to read real quotes from published authors.

Submit your manuscript here: https://www.dovepress.com/international-journal-of-general-medicine-journal 